\title{
DETERMINAÇÃO DE METODOLOGIAS PARA TESTE DE GERMINAÇÃO E VIGOR DE SEMENTES DE QUIXABEIRA (Bumelia obtusifolia ROEM ET SCHULT. VAR. EXCELSA (DC) MIG.) $)^{1}$
}

\author{
Irinaldo Lima Nascimento ${ }^{2}$
}

\begin{abstract}
RESUMO - Objetivou-se desenvolver metodologias para avaliação da qualidade de sementes de quixabeira que se encontra ameaçada de extinção, pelo fato de as cascas da árvore serem usadas na medicina popular. Foram realizados testes de secagem em laboratório e casa-de-vegetação por 0, 24, 48, 72, 96, 120, 144, 168 e 196 h de superação de dormência (escarificação com lixa; imersão em ácido sulfúrico por um, três, cinco e sete min; escarificação com lixa, seguida de embebição em água destilada por 12, 24, 36 e 48 h; embebição em água destilada por 12, 24, 36 e 48 h e testemunha) e com substratos (sobre e entre-areia, vermiculita, papel, bioplant ${ }^{\circledR}$, plantmax e rolo de papel germitest) em diferentes temperaturas $\left(20-30,30\right.$ e $\left.35^{\circ} \mathrm{C}\right)$. A secagem em casa de vegetação prejudicou a qualidade das sementes. A escarificação com lixa é o tratamento mais eficiente para superação da dormência. As temperaturas de $30^{\circ} \mathrm{C}$ com o substrato entre papel e $35^{\circ} \mathrm{C}$ com o substrato entre vermiculita são adequadas para testes de germinação com sementes de quixabeira.
\end{abstract}

Palavras-chave: Secagem; Dormência; Temperatura.

\section{DETERMINATION OF METHODOLOGIES FOR SEED GERMINATION AND VIGOR OF QUIXABEIRA (Bumel obtusifolia ROEM ET SCHULT. VAR. EXCELS (DC) MIG.)}

\begin{abstract}
The objective of this study was to develop methodologies for assessing the quality of Quixabeira seeds, which is a species threatened with extinction, due to the use of the tree bark in folk medicine. Drying tests were conducted in the laboratory and in a green-house for 0, 24, 48, 72, 96, 120, 144, 168 and 196 hours of overcoming seed dormancy (scarification; immersion in sulfuric acid for one, three, five and seven minutes; scarification followed by soaking in distilled water for 12, 24, 36 and 48 hours, soaking in distilled water for 12, 24, 36 and 48 hours and control) and with substrates (on and between-sand, vermiculite, paper, BioPlant ${ }^{\circledR}$, plantmax, and roll paper germitest) at different temperatures (20-30, 30 and $\left.35^{\circ} \mathrm{C}\right)$. Drying in greenhouse damaged the seeds quality. The scarification is the most effective treatment to overcome dormancy. Temperatures of $30^{\circ} \mathrm{C}$ with the substrate between the paper, and $35^{\circ} \mathrm{C}$ with the substrate in vermiculite are suitable for germination tests of Quixabeira seeds.
\end{abstract}

Keywords: Drying; Dormancy; Temperature.

\section{INTRODUÇÃO}

A quixabeira (Bumelia obtusifolia Roem et Schult. var. excelsa (DC) Mig., Sapotaceae) é uma árvore nativa da Caatinga. Embora tenha muitos espinhos duros, os rebanhos alimentam-se de suas folhas e frutos e, em várias regiões do Nordeste, a casca tem uso medicinal. Seu cultivo é por meio de sementes, mas a taxa de germinação geralmente é baixa em condições naturais, além de apresentar possível dormência tegumentar (SALIS; CRISPIM, 2006).

O conhecimento das condições ótimas de secagem, temperatura e substrato é de fundamental importância para germinação de espécies silvestres

\footnotetext{
${ }^{1}$ Recebido em 24.03.2011 aceito para publicação em 06.08.2013.

${ }^{2}$ Doutorando em agronomia da Universidade Federal do Ceará (UFC). E-mail: <iririlima@hotmail.com>.
} 
de frutos carnosos, pois essas características podem comprometer a produção homogênea e em alta quantidade (MORAES, 2000).

Entre as condições ambientais que afetam o processo germinativo, a temperatura é um dos fatores que têm influenciado significativamente. A temperatura afeta não apenas o total de germinação, como também a velocidade e uniformidade do processo. Dessa forma, são necessários conhecimentos referentes aos efeitos das diferentes temperaturas e às possíveis oscilações que possam ocorrer nesse período (SILVA et al., 2004), com a finalidade de delimitar valores em que a germinação não ocorre.

Segundo Assis (2010), a faixa ótima para germinação de sementes variadas está entre 15 e $30^{\circ} \mathrm{C}$ e a máxima entre 35 e $40^{\circ} \mathrm{C}$, podendo a mínima ir até pontos de congelamento. Villagra (1995) verificou que a temperatura ótima para germinação de sementes de nome comum (Prosopis argentina Burkart) e alarobila (P. alpataco Phil) é de $35^{\circ} \mathrm{C}$, enquanto as temperaturas ótimas para algaroba (P. juliflora (SW.) DC) ficam entre 30 e $35^{\circ} \mathrm{C}$ (PEREZ; MOARES, 1990). Outro fator determinante na porcentagem de germinação é o substrato, devido à estrutura, textura, aeração, capacidade de retenção de água e grau de infestação de patógenos (SCALON, 1992).

Este trabalho teve como objetivo avaliar a germinação e vigor de sementes de quixabeira em distintos tratamentos de secagem, quebra de dormência tegumentar e temperatura e substrato.

\section{MATERIAL E MÉTODOS}

A pesquisa foi realizada em laboratório, na Universidade Federal da Paraíba. Os frutos de quixabeira foram colhidos em janeiro e fevereiro, nas proximidades de Boa Vista, $07^{\circ} 15^{\prime} 32^{\prime \prime S}$ e 36¹4'24", no Agreste paraibano.

As sementes foram beneficiadas manualmente com o auxílio de água corrente, retirando-se a mucilagem presente no seu fruto e, em seguida, postas para secar em casa de vegetação, na temperatura de $32{ }^{\circ} \mathrm{C}$ e umidade de aproximadamente $47 \%$; e em laboratório, na temperatura de $28{ }^{\circ} \mathrm{C}$ e umidade de $46 \%$ durante $0,24,48,72,96,120$, 144, 168 e 196 h. Após cada período, determinou-se a umidade das sementes, pelo método da estufa a $105 \pm$ $3{ }^{\circ} \mathrm{C}$, durante $24 \mathrm{~h}$ (BRASIL, 1999), com quatro amostras contendo 10 sementes, assim como a germinação e o índice de velocidade de germinação ao longo do tempo.
As sementes apresentando dormência tegumentar foram submetidas à escarificação com lixa D’ água n 80; imersão em ácido sulfúrico por 1, 3, 5, 7 min, respectivamente; lixa +12, 24, 36 e 48 h de embebição em água destilada; embebição em água destilada por 12, 24, 36 e 48 h, respectivamente; e testemunha.

Foram testados os substratos sobre e entre areia, vermiculita, papel, bioplant ${ }^{\circledR}$, plantmax ${ }^{\circledR}$ e rolo de papel germitest, nas temperaturas de $20-30,30$ e $35^{\circ} \mathrm{C}$. No substrato papel, as sementes foram colocadas para germinar sobre duas folhas de papel, cobertas com uma terceira e disposta em forma de rolo, como também entre e sobre papel-filtro e semeadas em caixas plásticas transparentes de $11 \times 11$ x $3 \mathrm{~cm}$, com tampa. O papel foi umedecido com água destilada na quantidade de 2,5 vezes o seu peso seco.

Nos demais substratos, as sementes foram colocadas em caixas plásticas transparentes de 11 x 11 x $3 \mathrm{~cm}$, com tampa, sobre uma camada uniforme de areia lavada, vermiculita, bioplant ${ }^{\circledR}$ e plantmax ${ }^{\circledR}$ esterilizados e cobertas com uma camada de cerca de 2 cm e umedecida até $60 \%$ da capacidade de campo.

Os tratamentos foram avaliados mediante o percentual de germinação e índice de velocidade de germinação.

Germinação - Foram utilizadas 100 sementes por tratamento, divididas em quatro subamostras de 25, sendo empregadas como critério as plântulas normais que apresentavam as estruturas essenciais perfeitas (BRASIL, 1999), com os resultados expressos em porcentagem.

Índice de velocidade de emergência germinação - Foram realizadas contagens diárias durante 21 dias das plântulas normais, e o índice foi calculado conforme a fórmula proposta por Maguire (1962).

Os dados foram submetidos à análise de variância em medida repetida no tempo (tempo $\mathrm{x}$ ambiente), nos experimentos I e II. A comparação de médias no experimento I foi feita pelo teste de Tukey. Em seguida, realizou-se uma regressão linear; nos experimentos II e III, sendo a comparação de média comparada pelo teste de Scott Nott, todos os testes a 5\% de probabilidade.

\section{RESULTADOS}

O teor de água inicial das sementes recém-colhidas era de aproximadamente $25 \%$, o qual reduziu para valores próximos a $5 \%$ com apenas 24 horas de secagem em ambiente de casa de vegetação, indicando uma rápida 
perda de umidade. Quando a secagem foi em laboratório a mesma ocorreu de forma mais lenta, onde após 24 horas o teor de água das sementes se encontrava acima de $10 \%$, o qual reduziu para $8 \%$ após 48 e daí por diante se manteve constante.

Houve diferença dos períodos de secagem sobre a porcentagem de germinação das sementes nos dois ambientes, sendo a germinação superior apenas nos períodos de 24 e 168 h (Gráficos I e II). No índice de velocidade de germinação não ocorreram mudanças significativas, porém, em casa de vegetação, a germinação foi superior em relação ao ambiente de laboratório, respectivamente nos períodos de 24 e 120 h.
As maiores porcentagens de germinação foram obtidas quando se utilizaram os tratamentos de escarificação com lixa d'água ${ }^{\circ}$ 80, escarificação com lixa + imersão em água por 36 e 48 h e imersão em água destilada por $12 \mathrm{~h}$. Quanto ao índice de velocidade de germinação, a escarificação com lixa foi a mais indicada (Tabela I).

As maiores porcentagens de germinação foram obtidas quando utilizou-se o substrato entre vermiculita a $20-30^{\circ} \mathrm{C}$, sobre e entre vermiculita e papel a $30^{\circ} \mathrm{C}$, bem como entre vermiculita e sobre papel a $35^{\circ} \mathrm{C}$ (Tabela II).
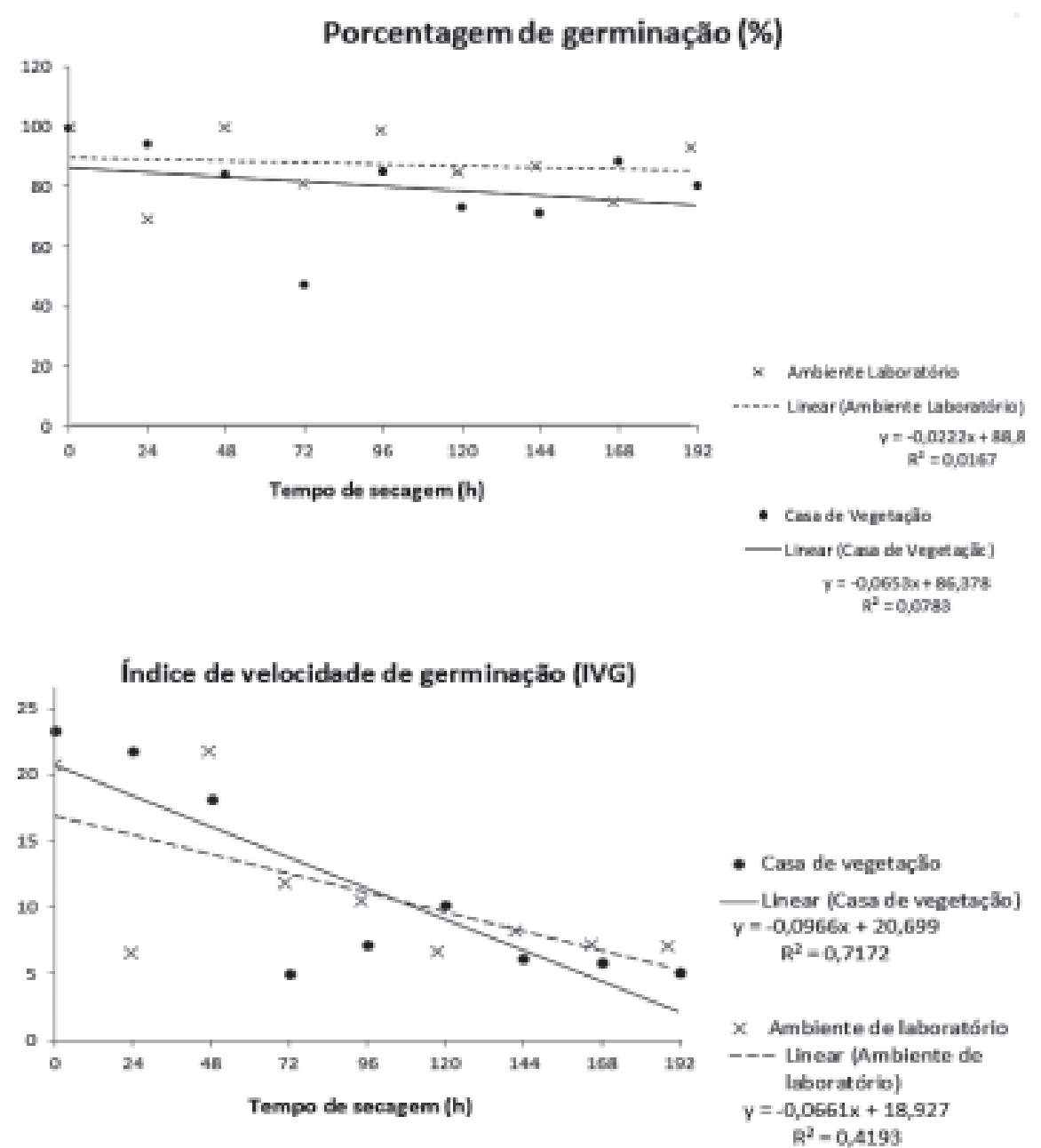

- Casa de vegetacllo

- Lhear (Casa de vegetacalo)

$y=-0,0966 x+20,699$ $R^{2}=0,7172$

$\times$ Ambiente de laboratório

-- Linear (Ambiente de

laborat óriol

$y=-0,0661 x+18,927$ $R^{2}=0,4193$

Figura 1 - Germinação e índice de velocidade de germinação (IVG) de sementes de quixabeira submetidas a diferentes ambientes de secagem.

Figure 1 - Germination and germination speed index (GSI) seed Quixabeira submitted to different drying environments. 
Tabela 1 - Germinação e índice de velocidade de germinação (IVG) de sementes de quixabeira submetidas a diferentes tratamentos pré-germinativos.

Table 1 - Germination and germination speed index (GSI) of quixabeira seed submitted to different pre-germination treatments.

\begin{tabular}{|c|c|c|}
\hline Tratamentos & Germinação (\%) & IVG \\
\hline Testemunha & $58 \mathrm{~b}$ & $5,75 \mathrm{c}$ \\
\hline Imersão em ácido sulfúrico por 1 minuto & $27 \mathrm{c}$ & $7,53 \mathrm{c}$ \\
\hline Imersão em ácido sulfúrico por 3 minutos & $56 \mathrm{~b}$ & $9,06 \mathrm{~b}$ \\
\hline Imersão em ácido sulfúrico por 5 minutos & $65 \mathrm{~b}$ & $12,00 \mathrm{~b}$ \\
\hline Imersão em ácido sulfúrico por 7 minutos & $66 \mathrm{~b}$ & $11,86 \mathrm{~b}$ \\
\hline Escarificação com lixa & 98 a & 21,92 a \\
\hline Escarificação com lixa + imersão em água por 12 horas & $10 \mathrm{~d}$ & $1,97 \mathrm{~d}$ \\
\hline Escarificação com lixa + imersão em água por 24 horas & $11 \mathrm{~d}$ & $2,05 \mathrm{~d}$ \\
\hline Escarificação com lixa + imersão em água por 36 horas & 87 a & $11,17 \mathrm{~b}$ \\
\hline Escarificação com lixa + imersão em água por 48 horas & 90 a & $11,40 \mathrm{~b}$ \\
\hline Imersão em água destilada por 12 horas & 83 a & $13,84 \mathrm{~b}$ \\
\hline Imersão em água destilada por 24 horas & $60 \mathrm{~b}$ & $10,16 \mathrm{~b}$ \\
\hline Imersão em água destilada por 36 horas & $37 \mathrm{c}$ & $4,22 \mathrm{~d}$ \\
\hline Imersão em água destilada por 48 horas & $19 \mathrm{~d}$ & $1,88 \mathrm{~d}$ \\
\hline
\end{tabular}

Médias seguidas de mesma letra na coluna não diferem estatisticamente entre si, a 5\% de probabilidade pelo teste de Scott Knott.

De acordo com os dados da Tabela 5, observaram-se, nas temperaturas de $20-30{ }^{\circ} \mathrm{C}$ associadas aos substratos sobre papel e rolo de $30^{\circ} \mathrm{C}$ com o substrato entre papel e $35^{\circ} \mathrm{C}$ nos substratos entre vermiculita e sobre papel, os maiores valores de velocidade de germinação.

\section{DISCUSSÃO}

A germinação inferior em casa de vegetação deveu-se, provavelmente, à exposição das sementes à alta temperatura e à alta umidade do ambiente, ocasionando, talvez, danos aos tecidos internos da semente. Santos e Alves (2010) constataram que sementes de mangaba (Hancornia speciosa. Gomes) são sensíveis à secagem em locais de alta temperatura, principalmente quando o período é prolongado, resultando em rápida perda de germinação.

No índice de velocidade de germinação, a baixa umidade nas sementes secas em casa de vegetação talvez possa ter comprometido as reações bioquímicas iniciais e, ou, aumentado a taxa respiratória da semente, dificultando posteriormente o processo de imersão do eixo embrionário. Segundo Dearman et al. (1987), processo de hidratação/desidratação da semente reduz a deterioração fisiológica e aumenta o potencial de armazenamento das sementes. No entanto, na secagem da semente os tonoplastos e plasmodesmas, que normalmente retêm solutos, perdem a sua integridade, deixando de agir como barreira durante a embebição
(BEWLEY; BLACK, 1992). Se esta for muito rápida ou extemporânea não ocorre a reconstituição delas, havendo perda dos solutos e consequente queda no vigor da semente (BEVILAQUA; PESKE, 1997).

Nos tratamentos para quebra de dormência, a escarificação com lixa foi eficiente em romper a camada impermeável das sementes, promovendo, assim, germinação e crescimento mais rápidos e uniformes. Bruno et al. (2001) constataram que os melhores resultados de germinação de sementes de Mimosa caesalpiniae folia Benth., sob a temperatura de $25^{\circ} \mathrm{C}$, ocorreram nos tratamentos de desponte, escarificação com lixa e imersão em ácido sulfúrico concentrado por 7, 10 e 13 min. Ainda segundo esses autores, a maior velocidade de germinação foi obtida com a imersão das sementes em ácido sulfúrico por 13 min. Em vários trabalhos, a escarificação mecânica foi empregada, com sucesso, na superação da dormência das sementes de Enterolobium contortisiliquum (Vell.) Morong (MONTEIRO, 1997).

A interação significativa entre a temperatura constante de $30^{\circ} \mathrm{C}$ e os substratos entre vermiculita e entre papel para o crescimento e germinação de sementes de quixabeira, resultados semelhantes foram obtidos por Albuquerque et al. (1998) com sementes de Colubria glandulosa Perk, já para Sebastiana commersoniana (Baill.) os resultados indicam máxima germinação quando as sementes foram submetidas ao substrato areia e a temperatura alternada de $20-30^{\circ} \mathrm{C}$ (SANTOS; AGUIAR, 
Tabela 2 - Germinação de sementes de quixabeira submetidas a diferentes substratos e temperaturas.

Table 2-Germination of quixabeira seeds submited to different substrates and temperatures.

\begin{tabular}{|c|c|c|c|}
\hline \multirow{3}{*}{ Substratos } & \multicolumn{3}{|c|}{ Temperaturas $\left({ }^{\circ} \mathrm{C}\right)$} \\
\hline & $20-30$ & 30 & 35 \\
\hline & \multicolumn{3}{|c|}{ Germinação (\%) } \\
\hline Sobre areia & 53 с B & 55 с A & $0 \mathrm{~g} \mathrm{C}$ \\
\hline Entre areia & 44 c B & 50 с A & 32 e $C$ \\
\hline Sobre vermiculita & $62 \mathrm{~b} \mathrm{~B}$ & 89 а $A$ & 30 e $C$ \\
\hline Entre vermiculita & 82 a $A$ & 93 а $A$ & 80 a $A$ \\
\hline Sobre bioplant ${ }^{\circledR}$ & $17 \mathrm{~d} \mathrm{C}$ & $32 \mathrm{~d} A$ & $20 \mathrm{f} \mathrm{B}$ \\
\hline Entre bioplant ${ }^{\circledR}$ & $5 \mathrm{~d} B$ & 3,0 e $B$ & $17 \mathrm{f} \mathrm{A}$ \\
\hline Sobre plantmax ${ }^{\circledR}$ & $17 \mathrm{~d} C$ & 56 с A & $40 \mathrm{~d} \mathrm{~B}$ \\
\hline Entre plantmax ${ }^{\circledR}$ & $10 \mathrm{~d} \mathrm{C}$ & $25 \mathrm{~d} B$ & $42 \mathrm{~d} A$ \\
\hline Sobre papel & $65 \mathrm{~b} \mathrm{~A}$ & 81 a $A$ & 76 a $\mathrm{A}$ \\
\hline Entre papel & $60 \mathrm{~b} \mathrm{~A}$ & 90 а $A$ & 53 с A \\
\hline Rolo de papel & 48 с B & $68 \mathrm{~b} \mathrm{~A}$ & $64 \mathrm{~b} \mathrm{~A}$ \\
\hline
\end{tabular}

Médias seguidas de mesma letra minúscula na coluna e maiúscula na linha não diferem a 5\% de probabilidade pelo teste de Scott Knott.

Tabela 3 - Índice de velocidade de germinação(IVG) de sementes de quixabeira submetidas a diferentes substratos e temperaturas.

Table 3 - Germination speed index (GSI) of quixabeira seed submited to different substrates and temperatures.

\begin{tabular}{lccc}
\hline \multirow{2}{*}{ Substratos } & \multicolumn{4}{c}{ Temperaturas $\left({ }^{\circ} \mathrm{C}\right)$} \\
\cline { 2 - 4 } & $20-30$ & 30 & 35 \\
\hline Sobre areia & $2,54 \mathrm{~d} \mathrm{~B}$ & 2,65 e A & $0,00 \mathrm{~g} \mathrm{C}$ \\
Entre areia & 1,72 e B & 4,47 d B & 4,82 b A \\
Sobre vermiculita & 2,86 d B & 5,88 c A & 1,35 f C \\
Entre vermiculita & 4,70 c B & 8,38 b A & 5,64 a A \\
Sobre bioplant ${ }^{\circledR}$ & 0,53 f A & 2,42 e C & 2,86 d B \\
Entre bioplant ${ }^{\circledR}$ & 0,21 e C & 0,20 g C & 0,77 f C \\
Sobre plantmax ${ }^{\circledR}$ & 1,50 f C & 2,42 e B & 4,25 c A \\
Entre plantmax ${ }^{\circledR}$ & 0,30 f C & 1,19 f C & 1,82 e C \\
Sobre papel & 7,93 a A & 8,66 b A & 2,95 d B \\
Entre papel & 6,12 b A & 10,33 a A & 2,49 d B \\
Rolo de papel & 7,63 a A & 6,46 c B & 3,94 c B \\
\hline
\end{tabular}

Médias seguidas de mesma letra minúscula na coluna e maiúscula na linha não diferem a 5\% de probabilidade pelo teste de Scott Knott.

2000). Temperaturas alternadas de $20-30^{\circ} \mathrm{C}$ nos substratos entre papel e sobre papel também apresentaram resultados significativos para a quixabeira. A Jatropha curcas L., também obteve bons resultados para a velocidade e porcentagem de germinação em temperaturas alternadas de $20-30^{\circ} \mathrm{C}$ (MARTINS; MACHADO, 2007). Assim como para aroeira (Myracrodruon urundeuva Allemão) as temperaturas de 20 a $30^{\circ} \mathrm{C}$ são as mais indicadas (SILVA et al., 2002). A temperatura constante de $35^{\circ} \mathrm{C}$ juntamente com o substrato entre vermiculita também apresentou um resultado interessante para os parâmetros avaliados. Esses resultados corroboram uma possível afirmação de que os efeitos da temperatura e do substrato são variáveis com a espécie e que está relacionado com o adequado desenvolvimento da plântula, influenciando a boa absorção de água pelas sementes e as reações bioquímicas que regulam os processos de germinação e crescimento (BEWLEY; BLACK, 1994).

\section{CONCLUSÃO}

A secagem em casa de vegetação prejudica a qualidade das sementes de quixabeira.

A escarificação com lixa é o tratamento mais eficiente para superação da dormência de sementes de quixabeira.

As temperaturas de $30^{\circ} \mathrm{C}$ com o substrato entre papel e entre vermiculita, $35^{\circ} \mathrm{C}$ com o substrato entre vermiculita são adequadas para testes de germinação com sementes de quixabeira.

\section{REFERÊNCIAS}

ALBUQUERQUE, U. P.; ANDRADE, L. H. C. Conhecimento botânico tradicional e conservação em uma área de caatinga no Estado de Pernambuco, Nordeste do Brasil. Acta Botancia Brasilica, v.16, n.3, p.273-285, 2002.

ALVES, E. U. et al. Germinação de sementes de Mimosa caesalpiniaefolia Benth. em diferentes substratos e temperaturas. Revista

Brasileira de Sementes, v.24, n.1, p.169178, 2002.

ASSIS, E. F.; LOURES, M. S. L. Germinação de sementes de Vellozia nanuzae, espécies endêmicas da serra do cipó, MG. 2010. 9p. Monografia (Graduação) Instituição Federal do Sul de Minas - Campus Inconfidentes, 2010.

BEWLEY, J. D.; BLACK, M. Physiology and biochemistry of seeds. New York: Spring Verlag, 1992. 390p. v.1.

BEWLEY, J. D.; BLACK, M. Seeds: physiology of development and germination. New York/ London: Plenum Press, 1994. 445p.

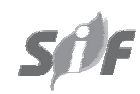

Revista Árvore, Viçosa-MG, v.37, n.4, p.701-706, 2013 
BEVILAQUA, G. A. P.; PESKE. S. T. Efeito da embebição-secagem de sementes de cenouras no vigor e potencial de armazenamento.

Revista Brasileira de Agrociência, v.3, n.3, p.131-138, 1997.

BRASIL. Ministério da Agricultura e Reforma Agrária. Regras para análise de sementes. Brasília: SNDA/DNDV/CLV, 1999. 365p.

BRUNO, R. L. A.; ALVES, E. U.; PAULA, R. C. Tratamento pré-germinativo para superar a dormência de sementes de Mimosa caesalpianifolia Benth. Revista Brasileira de Sementes, v.23, n.2, p.136-143, 2001.

CARVALHO, N. M.; NAKAGAWA, J. Sementes: ciência tecnológica e produção. Campinas: Fundação Cargill, 2000. 588p.

DEARMAN, J.; BROCKLEHURST, P. A.; DREW, R. L. K. Effects of osmotic priming and ageing on the germination and emergence of carrot and leek seeds. Annals of Applied Biology, v.111, p.717-722, 1987.

MAGUIRE, J. D. Speed of germination aid in selection and evaluation for seeding emergence and vigor. Crop Science, v.2, n.1, p.176-177, 1962.

MARTINS, C. C.; MACHADO C. G.; CAVASINI, R. Temperatura e substrato para o teste de germinação de sementes de pinhão-manso. Ciência Agrotêcnica, v.32, n.3, p.863-868, 2008.

MOARES, M. L. B. Comportamento da pressão estatística e da frente de sementes em uma coluna de sementes de arroz. 2000. 50f. Tese (Doutorado em Ciência e Tecnologia de Sementes) - UFPel/FAEM, Pelotas, 2000.

MONTEIRO, P. P. M.; RAMOS, F. A. Beneficiamento e quebra de dormência de sementes de cinco espécies florestais do cerrado. Revista Árvore, v.21, n.2, p.169-174, 1997.
PEREZ, S. C J. G. A.; MORAES, J. A. P. V. Influências da temperatura, da interação temperatura-giberelina e do estresse térmico na germinação de Prosopis juliflora (Sw.) D.C. Revista Brasileira de Fisiologia Vegetal, v. 2, n. 1, p. 41-53, 1990.

SALES, S.M.; CRISPIN, S.M.A. Densidades de arvores listadas como ameaçadas de extinção na bacia do alto Paraguai. Corumba, MS: Embrapa. 2006. (Comunicado Técnico, 54)

SANTOS, P. C. G. et al. Qualidade de sementes de Hancornia speciosa. Gomes em função do tempo de secagem. Ciências Agrárias, v.31, n.2, p.343-352, 2010.

SANTOS, S. R. G.; AGUIAR, I. B. Germinação de sementes de branquilho (Sebastiania commersoniana (Baill.) Smith e Downs) em função do substrato e do regime de temperatura. Revista Brasileira de Sementes, v.22, n.1, p.120-126, 2000.

SCALON, S. P. Q. Estudo da germinação de sementes e produção de mudas de pau-pereira (Platycyamus regnelli Benth). 1992. 630f. Dissertação (Mestrado em agronomia) - Escola Superior de Agricultura de Lavras, Lavras, 1992.

SILVA, L. M. M.; AGUIAR, I. B. Efeito dos substratos e temperaturas na germinação de sementes de Cnidosculus phyllancanthus Pax \& K. Hoffm (faveleira). Revista Brasileira de Sementes, v.26, n.1, p.9-14, 2004.

SILVA, L. M. M.; RODRIGUES, T. J. D.; AGUIAR, I. B. Efeito da luz da temperatura na germinação de sementes de aroeira (Myracrodruon urundeuva Allemão). Revista Árvore, v.26, n.6, p.691-697, 2002.

VILLAGRA, P. E. Temperature effects on germination of Prosopis argentina and P. alpataco (Fabaceae, Mimosoideae). Seed Science and Technology, v.23, n.3, p.636-646, 1995. 